\title{
Effect of treadmill gait on bone markers and bone mineral density of quadriplegic subjects
}

D.C.L. Carvalho ${ }^{1}$,

C.R. Garlipp ${ }^{2}$, P.V. Bottini ${ }^{3}$,

S.H. Afaz ${ }^{3}$, M.A. Moda ${ }^{3}$ and A. Cliquet Jr. ${ }^{1,4}$

\author{
${ }^{1}$ Departamento de Ortopedia e Traumatologia, ${ }^{2}$ Departamento de Patologia Clínica, \\ Faculdade de Ciências Médicas, ${ }^{3}$ Divisão de Patologia Clínica, Hospital Universitário, \\ Universidade Estadual de Campinas, Campinas, SP, Brasil \\ ${ }^{4}$ Departamento de Engenharia Elétrica, Universidade de São Paulo, São Carlos, \\ SP, Brasil
}

Correspondence

D.C.L. Carvalho

Departamento de Ortopedia e

Traumatologia

FCM, UNICAMP

Rua Alexander Fleming, 181

13083-970 Campinas, SP

Brasil

Fax: $+55-19-3788-7505$

E-mail: dclcarvalho@yahoo.com.br

Research supported by FAPESP (Nos. 2005/53530-0, 2003/05856-9 and $1996 / 12198-2)$.

Received March 3, 2006 Accepted August 21, 2006

\begin{abstract}
Quadriplegic subjects present extensive muscle mass paralysis which is responsible for the dramatic decrease in bone mass, increasing the risk of bone fractures. There has been much effort to find an efficient treatment to prevent or reverse this significant bone loss. We used 21 male subjects, mean age $31.95 \pm 8.01$ years, with chronic quadriplegia, between $\mathrm{C} 4$ and $\mathrm{C} 8$, to evaluate the effect of treadmill gait training using neuromuscular electrical stimulation, with 30-50\% weight relief, on bone mass, comparing individual dual-energy X-ray absorptiometry responses and biochemical markers of bone metabolism. Subjects were divided into gait $(\mathrm{N}=11)$ and control $(\mathrm{N}=10)$ groups. The gait group underwent gait training for 6 months, twice a week, for $20 \mathrm{~min}$, while the control group did not perform gait. Bone mineral density (BMD) of lumbar spine, femoral neck, trochanteric area, and total femur, and biochemical markers (osteocalcin, bone alkaline phosphatase, pyridinoline, and deoxypyridinoline) were measured at the beginning of the study and 6 months later. In the gait group, $81.8 \%$ of the subjects presented a significant increase in bone formation and $66.7 \%$ also presented a significant decrease of bone resorption markers, whereas $30 \%$ of the controls did not present any change in markers and $20 \%$ presented an increase in bone formation. Marker results did not always agree with BMD data. Indeed, many individuals with increased bone formation presented a decrease in BMD. Most individuals in the gait group presented an increase in bone formation markers and a decrease in bone resorption markers, suggesting that gait training, even with 30-50\% body weight support, was efficient in improving the bone mass of chronic quadriplegics.
\end{abstract}

\section{Introduction}

Many investigations (1-3) have been carried out in order to find methods for gait recovery after spinal cord injury. However, subjects who suffer a spinal cord injury pres-
Key words

- Quadriplegic gait

- Electrical stimulation

- Osteoporosis

- Rehabilitation -........................... 
contraction and mechanical load results in decreased BMD below the injury level (11).

Previous studies (12-17) have evaluated the effect of neuromuscular electrical stimulation (NMES) on bone density. Mohr et al. (12) and Bloomfield et al. (13), observed an improvement in BMD after NMES-cycling intervention. However, Leeds et al. (14) and Eser et al. (15) did not observe any differences after treatment. Different responses have been attributed to the different training protocols used (18).

Dual-energy X-ray absorptiometry (DEXA) has been extensively used to evaluate BMD and to monitor the effects of treatment on bone sites (19). Despite the high precision, low irradiation dose and fast scanning time, studies have suggested that even with a low precision error $(20,21)$, depending on the expected rate of bone gain, a 1- to 2-year interval between exams would be required for an accurate identification of changes in bone mass due to the fact that densitometry is slow in revealing bone alterations (22-25). However, it is possible to use DEXA at short testing intervals to assess bone changes following spinal cord injury since the rate of bone loss is typically rapid and large relative to the precision error. Many studies have analyzed the effect of short periods of treatment on bone density in spinal cord-injured subjects using DEXA (13, 14,26).

Biochemical markers of bone turnover have been used to evaluate bone metabolism (27-29) since they respond to treatment more rapidly than bone density (30-32). Significant differences can be noted within 3-6 months of treatment (33). Bone markers measure the rate of bone turnover when the events of bone resorption and formation are coupled. However, when the events are uncoupled they reflect the increase in either bone formation or bone resorption (34). Hence, the uncoupled increase of osteocalcin, for instance, represents an increase in bone formation rate (30).
NMES allows the activation of paralyzed muscles in order to perform physical activities such as pedaling on a bicycle ergometer and gait $(35,36)$. For quadriplegic subjects, gait training can be achieved using body weight support (BWS), which provides trunk stability and allows the control of the weight that can be supported by the lower limbs of each patient, thus reducing the risk of fracture in osteoporotic bones $(3,37)$.

In view of the lack of studies on this topic, the purpose of the present investigation was to evaluate the effect of treadmill gait training with $30-50 \%$ of weight relief associated with NMES on the bone mass of quadriplegic subjects and to determine whether individual responses are similar when BMD measured by DEXA is compared with biochemical markers of bone metabolism.

\section{Material and Methods}

Twenty-one male quadriplegic subjects (mean age $31.95 \pm 8.01$ years) participated in the study. The injury level varied between $\mathrm{C} 4$ and $\mathrm{C} 8(\mathrm{C} 4, \mathrm{~N}=4 ; \mathrm{C} 5, \mathrm{~N}=4 ; \mathrm{C} 6, \mathrm{~N}=9$; $\mathrm{C} 7, \mathrm{~N}=3 ; \mathrm{C} 8, \mathrm{~N}=1)$. In the gait group $(\mathrm{GG})$, all individuals had a complete lesion. In the control group (CG) all individuals had an incomplete lesion (ASIA Impairment Scale: B). Mean time post-injury was $66.42 \pm 48.23$ months (range 25-180 months). Mean body mass and height were $63.52 \pm 9.41 \mathrm{~kg}$ and $176.28 \pm 5.28 \mathrm{~cm}$, respectively. The study was approved by the local Ethics Committee and all subjects gave written informed consent to participate. Inclusion criteria were intact lower motor neurons required for muscle contraction using surface electrical stimulation and to permit walking for treadmill gait, with 30-50\% BWS for 20 consecutive min, with no skin damage or ulcers. Another requirement was no history of cardiopulmonary disease. Radiological and clinical examinations of the lower limbs were performed to guarantee that no subject had 
fractures, joint degeneration changes or clinical joint instability.

The individuals were divided into two groups: $\mathrm{GG}$ and $\mathrm{CG}$. GG individuals ( $\mathrm{N}=$ 11) were submitted to treadmill gait training provided by NMES for 6 months, twice a week, 20 min per session, whereas CG individuals $(\mathrm{N}=10)$ were not submitted to gait training. GG subjects had their quadriceps and tibialis anterior muscles stimulated for at least 5 months before beginning gait training (twice a week) in order to be able to walk for $20 \mathrm{~min}$, as well as to support at least $50 \%$ of their body weight through knee extension provided by NMES (pregait training). A 4channel electrical stimulator delivered a 25 $\mathrm{Hz}$ signal with monophasic rectangular pulses of 300- $\mu$ s duration and a maximum intensity of $200 \mathrm{~V}$ ( $1 \mathrm{k} \Omega$ load).

BWS was provided by a harness hanging from an overhead support, and the support vest allowed free movement of the lower limbs. The body weight support was 30 to $50 \%$. The four-channel electrical stimulator was used to provide the stance gait phase through quadriceps muscle activation and the swing phase by the withdrawal reflex (stimuli to the common peroneal nerve). Manual assistance during treadmill walking was provided to all patients in order to allow a safe and closer to normal pattern of gait. Surface electrodes $\left(5 \times 9 \mathrm{~cm}^{2}\right)$ were placed on the quadriceps and over the common peroneal nerve (round electrodes $3.2 \mathrm{~cm}$ in diameter). The stimulation unit was triggered by hand switches controlled by the staff.

$\operatorname{BMD}\left(\mathrm{g} / \mathrm{cm}^{2}\right)$ was determined by DEXA using a DPX-ALPHA Lunar Apparatus (DeWitt, MI, USA). The BMD of the lumbar spine (L2-L4), proximal femur (femoral neck and trochanteric area) and total femur was analyzed. The precision error was $1.0 \%$ for the lumbar spine, $1.37 \%$ for the femoral neck, $1.7 \%$ for the trochanteric area, and $1.5 \%$ for the femur. The least significant changes (LSC) were $2.77 \%$ for the lumbar spine, $3.80 \%$ for the femoral neck, $4.59 \%$ for the trochanteric area, and $4.15 \%$ for the total femur. The coefficient of variation was determined from three repeated measurements of the 5 spinal cord-injured subjects included in the study on 3 separate days (95\% confidence interval) $(12,13,15)$. All exams were performed by the same technician at the beginning of the study and 6 months later. Biochemical markers of bone turnover were also evaluated. Serum osteocalcin (OC) and bone alkaline phosphatase (B-ALP), both markers of bone formation, and free pyridinoline (PYD) and free deoxypyridinoline (DPD), both markers of bone resorption, were analyzed. PYD and DPD were corrected for creatinine and are reported as $\mathrm{nmol} / \mathrm{mmol}$. Bone markers were measured by an immunoassay method (Metra Biosystems, Mountain View, CA, USA). Serum and urine samples were collected between 8:00 and 10:00 am after an overnight fast and stored at $-80^{\circ} \mathrm{C}$ until analysis. The measurements were made at the beginning of the study and 6 months later.

Data were analyzed separately for each individual, because each subject presented different bone responses, since BMD is influenced by many factors as nutrition, bone condition before lesion, physical activity, and body weight, which is an important factor for bone mass variability (15-32\%) (38).

Bone markers and BMD results were considered to be significant when differences between the initial and final values were higher than the LSC (34). Bone marker values were analyzed based on the study of Hannon et al. (33), who observed that the LSC, within a single individual, was $21 \%$ from baseline values for OC, $28 \%$ for BALP, $36 \%$ for PYD, and $26 \%$ for DPD (95\% confidence interval).

\section{Results}

Table 1 presents the biochemical markers of bone formation and resorption for 
each GG and CG subjects. The results showed a significant increase in bone formation markers after gait training in $81.8 \%$ (9 individuals) of the subjects, with $66.7 \%$ (8 individuals) presenting a significant decrease in bone resorption markers. However, in many cases, despite the increased bone formation rate and decreased bone resorption markers, resorption marker values were higher than reference values. Reference values were 3.7$10.0 \mathrm{ng} / \mathrm{mL}$ for OC, $12-41 \mathrm{U} / \mathrm{L}$ for B-ALP, $12-37 \mathrm{nmol} / \mathrm{mmol}$ for PYD/Cr, and $2-7 \mathrm{nmol} /$ $\mathrm{mmol}$ for DPD/Cr. Moreover, one subject presented a decrease in bone turnover and one presented a decrease in bone resorption rate.

In the $\mathrm{CG}$, no alterations were observed in $30 \%$ of the individuals (3 individuals), while $20 \%$ ( 2 individuals) presented a significant increase in bone formation markers. CG individuals who presented an increase of formation markers increased their independence during daily activities (they managed to obtain driver licenses and became less dependent on accompanying persons) during the 6-month period. A decrease in bone resorption markers was noted in $30 \%$ of subjects ( 3 individuals). One subject showed increased bone resorption markers and another showed decreased bone formation markers.

Table 2 presents the results of BMD (g/ $\mathrm{cm}^{2}$ ) at the beginning and after 6 months of GG and CG. The results obtained with biochemical markers were not always reproduced in BMD. Of the individuals who presented an increase in bone formation markers $(\mathrm{N}=9), 3$ presented a BMD gain at most of the sites analyzed (individuals 3, 4, and 5), 4 presented loss of BMD at most of the sites analyzed (individuals 1, 6, 7, and 8), 1 (individual 9) presented maintenance of BMD except for total femur, which lost bone mass, and 1 (individual 2) presented maintenance of BMD except for the femoral neck, which gained bone mass. The total femur of individual 10 was not evaluated.

In the $\mathrm{CG}$, at the beginning of the study and 6 months later, one subject could not have his femur evaluated because of a flexor contracture of his hip. Of the two individuals who presented a significant increase in bone formation markers, one presented an increase and the other a decrease in BMD. Even among those who did not present any alteration of bone markers (when comparing ini-

Table 1. Biochemical markers of bone formation and resorption for each subject of gait group ( $G G, N=11)$ and control group (CG, $N=10$ ) before and after 6 months.

\begin{tabular}{|c|c|c|c|c|c|c|c|c|c|c|c|c|c|c|c|c|}
\hline \multirow[t]{3}{*}{ Subjects } & \multicolumn{4}{|c|}{$\begin{array}{l}\text { Osteocalcin } \\
\text { (ng/mL) }\end{array}$} & \multicolumn{4}{|c|}{$\begin{array}{l}\text { Bone alkaline phosphatase } \\
\qquad(\mathrm{U} / \mathrm{L})\end{array}$} & \multicolumn{4}{|c|}{$\begin{array}{l}\text { Free pyridinoline } \\
\qquad(\mathrm{nmol} / \mathrm{mmol})\end{array}$} & \multicolumn{4}{|c|}{$\begin{array}{l}\text { Free deoxypyridinoline } \\
\text { (nmol/mmol) }\end{array}$} \\
\hline & \multicolumn{2}{|c|}{$\mathrm{GG}$} & \multicolumn{2}{|c|}{ CG } & \multicolumn{2}{|c|}{ GG } & \multicolumn{2}{|c|}{ CG } & \multicolumn{2}{|c|}{$\mathrm{GG}$} & \multicolumn{2}{|c|}{ CG } & \multicolumn{2}{|c|}{$\mathrm{GG}$} & \multicolumn{2}{|c|}{ CG } \\
\hline & Before & After & Before & After & Before & After & Before & After & Before & After & Before & After & Before & After & Before & After \\
\hline 1 & 5.23 & 6.55 & 4.45 & 4.50 & 28.98 & 25.13 & 15.58 & 13.28 & 55.30 & 30.52 & 57.65 & 38.05 & 9.98 & 8.24 & 5.26 & 11.49 \\
\hline 2 & 8.40 & 23.61 & 4.56 & 8.25 & 34.05 & 33.24 & 23.55 & 26.96 & 85.02 & 41.88 & 62.41 & 39.04 & 5.95 & 5.79 & 8.61 & 8.36 \\
\hline 3 & 4.42 & 8.89 & 4.48 & 3.92 & 22.70 & 28.59 & 19.79 & 17.95 & 52.60 & 37.04 & 44.30 & 29.65 & 6.11 & 5.66 & 6.38 & 5.36 \\
\hline 4 & 4.52 & 6.55 & 4.58 & 4.60 & 28.23 & 32.08 & 16.47 & 14.76 & 50.22 & 38.24 & 38.80 & 27.34 & 6.07 & 4.15 & 16.39 & 6.42 \\
\hline 5 & 4.42 & 7.16 & 4.43 & 4.84 & 21.57 & 27.44 & 12.66 & 10.26 & 25.04 & 16.94 & 48.35 & 35.76 & 5.75 & 2.82 & 18.24 & 12.46 \\
\hline 6 & 7.80 & 13.81 & 6.18 & 17.47 & 25.50 & 23.58 & 21.38 & 28.16 & 203.47 & 161.26 & 56.58 & 52.06 & 27.3 & 24.34 & 9.23 & 10.47 \\
\hline 7 & 6.79 & 10.81 & 4.49 & 5.01 & 19.75 & 18.42 & 25.77 & 27.74 & 179.64 & 96.72 & 69.17 & 58.25 & 30.33 & 18.28 & 13.85 & 11.37 \\
\hline 8 & 5.79 & 11.19 & 4.38 & 4.37 & 22.04 & 26.19 & 31.49 & 27.80 & 40.87 & 40.92 & 43.11 & 35.44 & 22.82 & 8.20 & 12.06 & 9.38 \\
\hline 9 & 4.51 & 7.13 & 4.58 & 4.48 & 16.08 & 15.29 & 31.10 & 31.26 & 41.86 & 27.54 & 43.41 & 22.89 & 4.39 & 2.69 & 7.45 & 4.99 \\
\hline 10 & 6.81 & 4.57 & 4.45 & 3.47 & 18.67 & 17.08 & 10.44 & 7.02 & 60.74 & 35.17 & 55.95 & 37.02 & 8.17 & 6.95 & 6.30 & 7.61 \\
\hline 11 & 6.72 & 6.72 & - & - & 19.05 & 23.41 & - & - & 56.59 & 46.84 & - & - & 14.64 & 10.02 & - & - \\
\hline
\end{tabular}


tial and final values), some presented a gain of BMD and some lost or maintained their BMD.

\section{Discussion}

The present results show that treadmill gait training was efficient in increasing the rate of bone formation, even with 30-50\% of BWS, since most individuals presented a significant increase of OC (a bone formation marker) and a decrease of PYD and/or DPD (bone resorption markers). Since the results for the bone markers presented a dissociation of bone resorption and formation events, they represented an increase of bone formation rate $(30,34)$. The increase in bone formation rate is associated with gait training and not with pregait training since NMES used to provide knee extension without any resistance has been shown not to improve bone density in many studies $(13,39)$.

All individuals had sustained their injuries at least 25 months before the study and, based on the literature, bone loss occurs dramatically during the first 3-4 months postinjury (22-27\% depletion) and bone mass achieves a new steady state by 16 months after the injury, with approximately $37 \%$ bone depletion. Garland et al. (40) did not observe any significant differences in bone mass between 16 months and 10 years postinjury.

Some individuals included in our study (6 months between DEXA measurements) presented a significant decrease of bone mass, i.e., a reduction of $20.46 \%$ in the femoral neck and of $29.95 \%$ in the trochanteric area. These dramatic decreases of bone mass may reflect the imprecision of DEXA due to the short time between measurements or due to the problems that occur during densitometry exams in spinal cord-injured persons (spasticity and lack of reproducibility of lower limb position).

Bloomfield et al. (13) also observed that some quadriplegic individuals submitted to NMES-cycle ergometer training presented a bone loss at one or more bone sites analyzed during 9 months of physical activity. They hypothesized that insufficient calcium intake could have been responsible for the increased bone loss since the maintenance of mineral homeostasis (extracellular calcium ion concentration) is essential for body function.

Table 2. Bone mineral density (BMD) values $\left(\mathrm{g} / \mathrm{cm}^{2}\right)$ obtained before and after 6 months for each subject of gait group (GG, $\left.N=11\right)$ and control group (CG, $N=10$ ) for lumbar spine (L2-L4), femoral neck, trochanteric area, and total femur.

\begin{tabular}{|c|c|c|c|c|c|c|c|c|c|c|c|c|c|c|c|c|}
\hline \multirow[t]{3}{*}{ Subjects } & \multicolumn{4}{|c|}{ Lumbar spine } & \multicolumn{4}{|c|}{ Femoral neck } & \multicolumn{4}{|c|}{ Trochanteric area } & \multicolumn{4}{|c|}{ Total femur } \\
\hline & \multicolumn{2}{|c|}{ GG } & \multicolumn{2}{|c|}{ CG } & \multicolumn{2}{|c|}{ GG } & \multicolumn{2}{|c|}{ CG } & \multicolumn{2}{|c|}{$\mathrm{GG}$} & \multicolumn{2}{|c|}{ CG } & \multicolumn{2}{|c|}{ GG } & \multicolumn{2}{|c|}{ CG } \\
\hline & Before & After & Before & After & Before & After & Before & After & Before & After & Before & After & Before & After & Before & After \\
\hline 1 & 1.353 & 1.345 & 1.456 & 1.402 & 0.923 & 0.863 & NE & NE & 0.723 & 0.652 & NE & NE & 0.935 & 0.851 & NE & $\mathrm{NE}$ \\
\hline 2 & 1.447 & 1.473 & 1.239 & 1.197 & 0.756 & 0.795 & 0.759 & 0.692 & 0.574 & 0.561 & 0.461 & 0.438 & 0.686 & 0.682 & 0.628 & 0.570 \\
\hline 3 & 0.902 & 0.866 & 1.278 & 1.283 & 0.253 & 0.334 & 0.795 & 0.679 & 0.319 & 0.386 & 0.592 & 0.554 & 0.389 & 0.385 & 0.763 & 0.627 \\
\hline 4 & 1.303 & 1.333 & 1.184 & 1.170 & 0.674 & 0.673 & 0.790 & 0.815 & 0.461 & 0.458 & 0.529 & 0.497 & 0.686 & 0.721 & 0.663 & 0.670 \\
\hline 5 & 0.993 & 0.983 & 1.099 & 1.110 & 0.677 & 0.699 & 0.647 & 0.669 & 0.483 & 0.516 & 0.453 & 0.445 & 0.638 & 0.654 & 0.543 & 0.537 \\
\hline 6 & 1.173 & 1.180 & 1.143 & 1.144 & 1.114 & 0.886 & 0.422 & 0.523 & 0.694 & 0.554 & 0.285 & 0.416 & 0.953 & 0.774 & 0.557 & 0.513 \\
\hline 7 & 1.132 & 1.132 & 0.996 & 1.011 & 0.977 & 0.904 & 0.573 & 0.568 & 0.723 & 0.610 & 1.740 & 1.702 & 0.863 & 0.831 & 1.156 & 1.175 \\
\hline 8 & 1.240 & 1.287 & 1.707 & 1.708 & 0.856 & 0.796 & 1.115 & 1.068 & 0.603 & 0.535 & 0.793 & 0.770 & 0.801 & 0.760 & 0.973 & 0.961 \\
\hline 9 & 1.092 & 1.085 & 1.102 & 1.085 & 0.603 & 0.600 & 0.641 & 0.644 & 0.523 & 0.522 & 0.539 & 0.547 & 0.608 & 0.592 & 0.717 & 0.717 \\
\hline 10 & 1.221 & 1.221 & 1.062 & 1.033 & 1.079 & 1.022 & 0.603 & 0.654 & 0.685 & 0.655 & 0.491 & 0.479 & NE & NE & 0.603 & 0.586 \\
\hline 11 & 1.158 & 1.162 & - & - & 0.838 & 0.692 & - & - & 0.681 & 0.477 & - & - & 0.840 & 0.647 & - & - \\
\hline
\end{tabular}

$\mathrm{NE}=$ not evaluated 
As shown in Table 1, it is clear that there was a reduction in bone marker resorption in the GG subjects, meaning that the calcium intake was not the reason for the bone loss observed by DEXA.

The present results show that treadmill gait provided by NMES associated with partial body weight support was efficient in increasing the bone formation markers together with a decrease of bone resorption markers in quadriplegic subjects.

\section{References}

1. Wickelgren I. Teaching the spinal cord to walk. Science 1998; 279 : 319-321.

2. Field-Fote EC, Tepavac D. Improved intralimb coordination in people with incomplete spinal cord injury following training with body weight support and electrical stimulation. Phys Ther 2002; 82: 707-715.

3. Field-Fote EC. Combined use of body weight support, functional electric stimulation, and treadmill training to improve walking ability in individuals with chronic incomplete spinal cord injury. Arch Phys Med Rehabil 2001; 82: 818-824.

4. Figoni SF. Exercise responses and quadriplegia. Med Sci Sports Exerc 1993; 25: 433-441.

5. Dallmeijer AJ, Hopman MT, van As HH, van der Woude LH. Physical capacity and physical strain in persons with tetraplegia; the role of sport activity. Spinal Cord 1996; 34: 729-735.

6. Kiratli BJ, Smith AE, Nauenberg T, Kallfelz CF, Perkash I. Bone mineral and geometric changes through the femur with immobilization due to spinal cord injury. J Rehabil Res Dev 2000; 37: 225-233.

7. Frey-Rindova P, de Bruin ED, Stussi E, Dambacher MA, Dietz V. Bone mineral density in upper and lower extremities during 12 months after spinal cord injury measured by peripheral quantitative computed tomography. Spinal Cord 2000; 38: 26-32.

8. Carvalho DCL, Carvalho MM, Cliquet A Jr. Disuse osteoporosis: Its relationship to spine cord injured patient rehabilitation. Acta Ortop Bras 2001; 9: 34-43.

9. Zehnder $\mathrm{Y}$, Luthi M, Michel D, Knecht $\mathrm{H}$, Perrelet R, Neto I, et al. Long-term changes in bone metabolism, bone mineral density, quantitative ultrasound parameters, and fracture incidence after spinal cord injury: a cross-sectional observational study in 100 paraplegic men. Osteoporos Int 2004; 15: 180-189.

10. Wilmet E, Ismail AA, Heilporn A, Welraeds D, Bergmann P. Longitudinal study of the bone mineral content and of soft tissue composition after spinal cord section. Paraplegia 1995; 33: 674-677.

11. Carvalho DC, Rosim GC, Gama LO, Tavares MR, Tribioli RA, Santos IR, et al. Non-pharmacological treatments in the stimulation of osteogenesis. Rev Saude Publica 2002; 36: 647-654.

12. Mohr T, Podenphant J, Biering-Sorensen F, Galbo H, Thamsborg G, Kjaer $\mathrm{M}$. Increased bone mineral density after prolonged electrically induced cycle training of paralyzed limbs in spinal cord injured man. Calcif Tissue Int 1997; 61: 22-25.

13. Bloomfield SA, Mysiw WJ, Jackson RD. Bone mass and endocrine adaptations to training in spinal cord injured individuals. Bone 1996; 19: 61-68.

14. Leeds EM, Klose KJ, Ganz W, Serafini A, Green BA. Bone mineral density after bicycle ergometry training. Arch Phys Med Rehabil 1990; 71: 207-209.

15. Eser P, de Bruin ED, Telley I, Lechner HE, Knecht H, Stussi E. Effect of electrical stimulation-induced cycling on bone mineral den- sity in spinal cord-injured patients. Eur J Clin Invest 2003; 33: 412419.

16. de Bruin ED, Frey-Rindova P, Herzog RE, Dietz V, Dambacher MA, Stussi E. Changes of tibia bone properties after spinal cord injury: effects of early intervention. Arch Phys Med Rehabil 1999; 80: 214220.

17. Belanger M, Stein RB, Wheeler GD, Gordon T, Leduc B. Electrical stimulation: can it increase muscle strength and reverse osteopenia in spinal cord injured individuals? Arch Phys Med Rehabil 2000; 81: 1090-1098.

18. Jiang SD, Dai LY, Jiang LS. Osteoporosis after spinal cord injury. Osteoporos Int 2006; 17: 180-192.

19. Seeley DG, Browner WS, Nevitt MC, Genant HK, Scott JC, Cummings SR. Which fractures are associated with low appendicular bone mass in elderly women? The Study of Osteoporotic Fractures Research Group. Ann Intern Med 1991; 115: 837-842.

20. Biering-Sorensen $\mathrm{F}$, Bohr $\mathrm{H}$, Schaadt $\mathrm{O}$. Bone mineral content of the lumbar spine and lower extremities years after spinal cord lesion. Paraplegia 1988; 26: 293-301.

21. Demirel G, Yilmaz H, Paker N, Onel S. Osteoporosis after spinal cord injury. Spinal Cord 1998; 36: 822-825.

22. Maimoun L, Couret I, Micallef JP, Peruchon E, Mariano-Goulart D, Rossi M, et al. Use of bone biochemical markers with dual-energy $\mathrm{X}$ ray absorptiometry for early determination of bone loss in persons with spinal cord injury. Metabolism 2002; 51: 958-963.

23. Johnston CC, Melton LJ III. Bone densitometry. In: Riggs BL, Melton LJ III (Editors), Osteoporosis: etiology, diagnosis, and management. 2nd edn. New York: Lippincott-Raven; 1995. p 275-297.

24. Wasnich RD. Epidemiology of osteoporosis. In: Favus MJ (Editor), Primer on the metabolic bone diseases and disorders of mineral metabolism. 4th edn. Philadelphia: Lippincott-Raven; 1999. p 257-259.

25. Garnero P, Delmas PD. Biochemical markers of bone turnover. Applications for osteoporosis. Endocrinol Metab Clin North Am 1998; 27: 303-323.

26. Kunkel CF, Scremin AM, Eisenberg B, Garcia JF, Roberts S, Martinez S. Effect of "standing" on spasticity, contracture, and osteoporosis in paralyzed males. Arch Phys Med Rehabil 1993; 74: 73-78.

27. Adachi JD. The correlation of bone mineral density and biochemical markers to fracture risk. Calcif Tissue Int 1996; 59: 16-19.

28. Watts NB. Clinical utility of biochemical markers of bone remodeling. Clin Chem 1999; 45: 1359-1368.

29. Inoue M, Tanaka H, Moriwake T, Oka M, Sekiguchi C, Seino $Y$. Altered biochemical markers of bone turnover in humans during 120 days of bed rest. Bone 2000; 26: 281-286.

30. Garnero P, Delmas PD. New developments in biochemical markers for osteoporosis. Calcif Tissue Int 1996; 59 (Suppl 1): S2-S9. 
31. Harris ST, Gertz BJ, Genant HK, Eyre DR, Survill TT, Ventura JN, et al. The effect of short term treatment with alendronate on vertebral density and biochemical markers of bone remodeling in early postmenopausal women. J Clin Endocrinol Metab 1993; 76: 1399-1406.

32. Mundy GR. Bone remodeling and its disorders. 2nd edn. London: Martin Dunitz; 1999.

33. Hannon R, Blumsohn A, Naylor K, Eastell R. Response of biochemical markers of bone turnover to hormone replacement therapy: impact of biological variability. J Bone Miner Res 1998; 13: 11241133.

34. Seibel MJ. Biochemical markers of bone metabolism in the assessment of osteoporosis: useful or not? J Endocrinol Invest 2003; 26: 464-471.

35. Petrofsky JS, Phillips CA, Heaton HH, Glaser RM. Bicycle ergometer for paralyzed muscle. J Clin Eng 1984; 9: 13-19.

36. Sepulveda F, Granat MH, Cliquet A Jr. Gait restoration in a spinal cord injured subject via neuromuscular electrical stimulation con- trolled by an artificial neural network. Int J Artif Organs 1998; 21: 4962.

37. Carvalho DC, de Cassia ZM, Sereni JM, Cliquet A. Metabolic and cardiorespiratory responses of tetraplegic subjects during treadmill walking using neuromuscular electrical stimulation and partial body weight support. Spinal Cord 2005; 43: 400-405.

38. Gerdhem P, Ringsberg KA, Akesson K, Obrant KJ. Influence of muscle strength, physical activity and weight on bone mass in a population-based sample of 1004 elderly women. Osteoporos Int 2003; 14: 768-772.

39. Pacy PJ, Hesp R, Halliday DA, Katz D, Cameron G, Reeve J. Muscle and bone in paraplegic patients, and the effect of functional electrical stimulation. Clin Sci 1988; 75: 481-487.

40. Garland DE, Stewart CA, Adkins RH, Hu SS, Rosen C, Liotta FJ, et al. Osteoporosis after spinal cord injury. J Orthop Res 1992; 10: 371-378. 